\title{
Minitaurized Reconfigurable Multiband Antennas For GPS, UMTS, WiMAX \& WLAN Wireless Applications
}

\author{
Manoj Kapil, Manish Sharma
}

\begin{abstract}
In this manuscript, compact multiband antenna for four different wireless applications is presented. Two stubs which are embedded on radiating patch produces resonances for Global Positioning System (GPS) and Universal Mobile Telecommunication system (UMTS). Also, the other two resonating bands are obtained by etching two slots which produces resonances for WiMAX and WLAN bands. Antenna offers good gain and radiation pattern at operating frequencies bands. Furthermore, to control resonating bands which are obtained by means of stubs and slots, antenna is reconfigured by using 4 PIN diodes. Antenna is designed on Rogers RT Duroid5870 with compact dimensions of $20 \times 20 \mathbf{~ m m}^{2}$.
\end{abstract}

Index Terms: GPS, UMTS, WiMAX, WLAN, RT Duroid, PIN

\section{INTRODUCTION}

As the demand for use of existing wireless applications like Global Positioning System (GPS), Universal Mobile Telecommunication System (UMTS), Bluetooth, WiMAX \& WLAN, need for single antenna covering all the above applications has also increased due to miniaturization of Printed Circuit Board (PCB). Literature survey reveals simple antenna presented in [1] provides operation for WiMAX and WLAN bands which also permits switching upto ten frequency bands between $2.20 \mathrm{GHz}-6.00 \mathrm{GHz}$. Area of the antenna occupies $50 \times 45 \mathrm{~mm}^{2}$ space of PCB and two PIN diodes are used to convert multiband antenna into reconfigurable characteristics. Also, four bands antenna based on loaded metamaterial and slots targets wireless applications such as GPS, WLAN and WiMAX wireless system occupying volume of $0.21 \lambda_{0} \times 0.23 \lambda_{0} \times 0.01 \lambda_{0}$ with designed center frequency of $2.40 \mathrm{GHz}$ [2]. Hexaband antenna resonating at $1.30 \mathrm{GHz}, 1.75 \mathrm{GHz}, 33.35 \mathrm{GHz}, 6.50 \mathrm{GHz}$ and $7.60 \mathrm{GHz}$ respectively is reported in [3] which uses three asymmetric fork-shaped radiating elements including U-type radiator with slit. Antenna designed on FR4 substrate with area $27 \times 24 \mathrm{~mm}^{2}$ having proximity coupled feed operates for LTE2300 (2.30GHz-2.40GHz), Bluetooth (2.400GHz-2.485GHz), WiMAX $(3.30 \mathrm{GHz}-3.70 \mathrm{GHz})$ and WLAN $(5.150 \mathrm{GHz}-5.825 \mathrm{GHz})$ wireless applications. Complete antenna consists of rectangular patch which is cornered truncated, microstrip feed (meandered) and DGS

Revised Manuscript Received on July 5, 2019.

Manoj Kapil, Computer Science Engineering, Swami Vivekanand Subharti University, Meerut, India, manojkapil@yahoo.com

Manish Sharma, Department of Electronics and Communication Engineering, SGT University, Gurugram, India. Diode numerous multiband antennas which are also reconfigured. A

(Defected Ground Structure) [4]. By cutting U-shape slots on radiating patch [5], tunable triple band antenna is obtained covering bands like $2.07 \mathrm{GHz}-2.60 \mathrm{GHz}, 2.86 \mathrm{GHz}-3.57 \mathrm{GHz}$ and $4.59 \mathrm{GHz}-5.39 \mathrm{GHz}$. Dual polarized antenna, one linearly polarized for UMTS, WLAN $(2.40 \mathrm{GHz})$ \& WiMAX $(3.50 \mathrm{GHz})$ and circularly polarized for GPS $(1.575 \mathrm{GHz}) / \mathrm{GLONASS}$ is result of three rectangular stubs fed by microstrip [6]. Also, three operating bands are obtained by means of pair of L-shaped slots and rectangular slots [7]. S-type fractal with three iterations results in resonance for $2.50 \mathrm{GHz}, 5.30 \mathrm{GHz}, 7.10 \mathrm{GHz}$ and $8.40 \mathrm{GHz}$ respectively. These applications targets Bluetooth, WiMAX and WLAN bands [8]. F-shaped radiator with defected ground plane results in triple band of operation intended to cover WiMAX and WLAN applications [9]. Ground plane and radiating patch over the antenna size of $30 \times 34 \times 0.8 \mathrm{~mm}^{3}$ is capable of covering UMTS, WiMAX and WLAN wireless applications [10]. L-U shaped slots on rectangular patch, combination of fractals (Koch Snowflake and Sierpinski Carpet) also results in multiband functional antennas [11-12]. Proposed work shows design of antenna on Silicon Substrate with compact dimension of $20 \times 20 \mathrm{~mm}^{2}$. Antenna offers four bands of operation for Bluetooth, WiMAX, WLAN and X Band applications.

\section{ANTENNA CONFIGURATION AND RECONFIGURABLE CHARACTERISTICS}

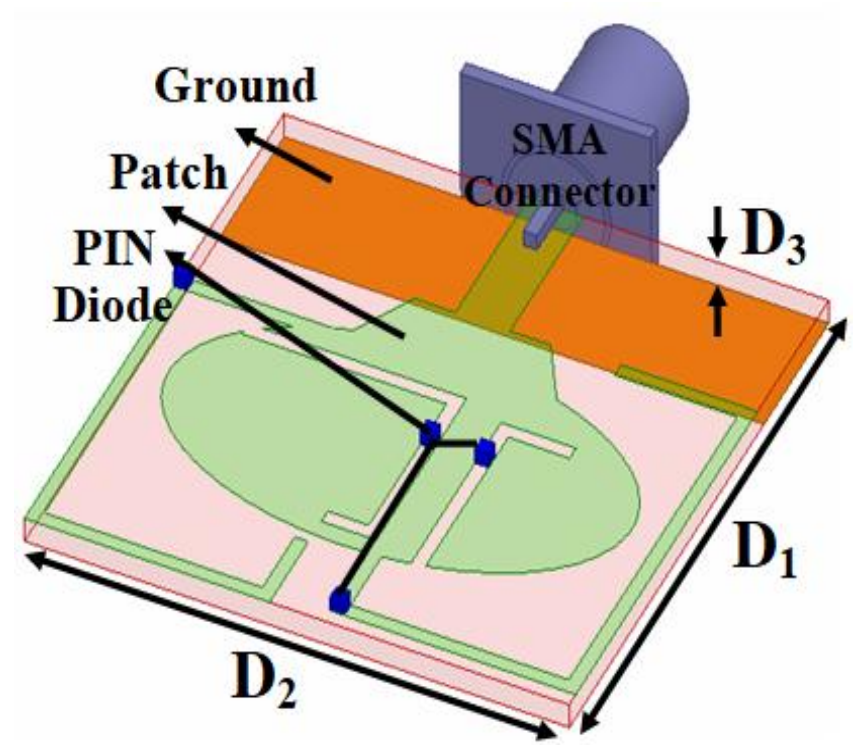

(a)

Published By: 


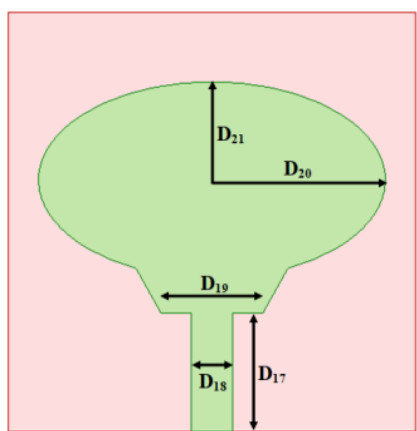

(b)

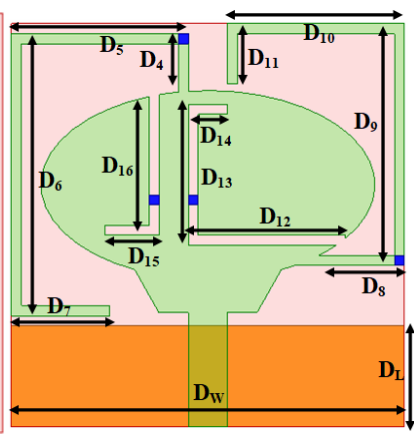

(c)
Fig.1. Antenna Configuration (a) Inclined Plane View (b) Designed Multiband Antenna (Front view without Multiband function) (c) Multiband Characteristics (Front view).

Complete antenna design is shown by Fig. 1 which illustrates explanation of designed antenna. Fig. 1(a) is inclined view of proposed antenna which shows radiating patch on one plane and ground on opposite plane of Microwave substrate Rogers RT Duroid5870 with electrical properties $\varepsilon_{\mathrm{r}}=2.33$ \& $\tan \delta=0.012$. Patch is fed by $50 \Omega$ microstrip line which has dimension of $\mathrm{D}_{16} \times \mathrm{D}_{17} \mathrm{~mm}^{2}$ and height $\mathrm{D}_{3} \mathrm{~mm}$. In order to achieve reconfigurable characteristics, four RF PIN diodes are used. Fig. 1(b) provides initial design to obtain single resonant frequency which is combination of partial hexagon and ellipse. Fig. 1(c) explain multifunctionality feature of designed antenna. Two stubs provides necessary resonance for GPS and UMTS wireless applications, whereas, two stubs etched on radiating patch results in WiMAX and WLAN wireless communication system. Furthermore, to convert multiband antenna to reconfigurable 4 PIN diodes are used by which individual wireless application band can be controlled (ON/OFF state of PIN diode). All the parameters shown in Fig. 1(a)-(c) are optimized by EM simulator Ansys HFSS and are tabulated in Table I:

Table I: Optimized Parameters

\begin{tabular}{|c|c|c|c|}
\hline Parameter & mm & Parameter & mm \\
\hline $\mathrm{D}_{1}$ & 20.00 & $\mathrm{D}_{13}$ & 7.00 \\
\hline $\mathrm{D}_{2}$ & 20.00 & $\mathrm{D}_{14}$ & 2.00 \\
\hline $\mathrm{D}_{3}$ & 0.787 & $\mathrm{D}_{15}$ & 2.75 \\
\hline $\mathrm{D}_{4}$ & 2.85 & $\mathrm{D}_{16}$ & 7.00 \\
\hline $\mathrm{D}_{5}$ & 9.00 & $\mathrm{D}_{17}$ & 20.00 \\
\hline $\mathrm{D}_{6}$ & 14.00 & $\mathrm{D}_{18}$ & 5.00 \\
\hline $\mathrm{D}_{7}$ & 5.00 & $\mathrm{D}_{19}$ & 5.67 \\
\hline $\mathrm{D}_{8}$ & 5.10 & $\mathrm{D}_{20}$ & 2.00 \\
\hline $\mathrm{D}_{9}$ & 12.00 & $\mathrm{D}_{21}$ & 5.00 \\
\hline $\mathrm{D}_{10}$ & 9.00 & $\mathrm{D}_{\mathrm{W}}$ & 8.50 \\
\hline $\mathrm{D}_{11}$ & 3.00 & $\mathrm{D}_{\mathrm{L}}$ & 4.675 \\
\hline
\end{tabular}

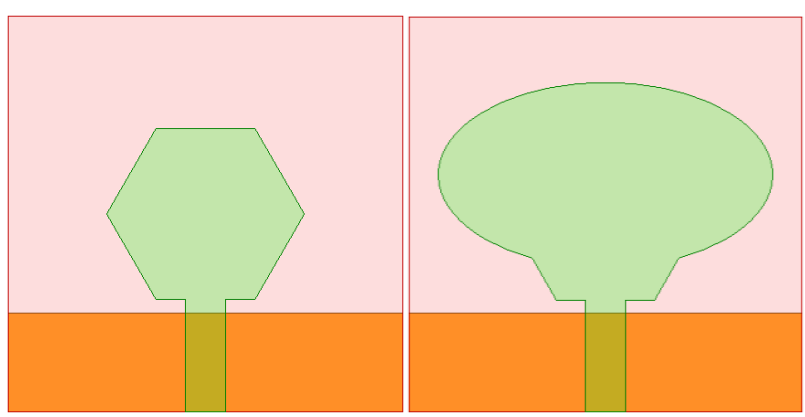

(a)

(b)

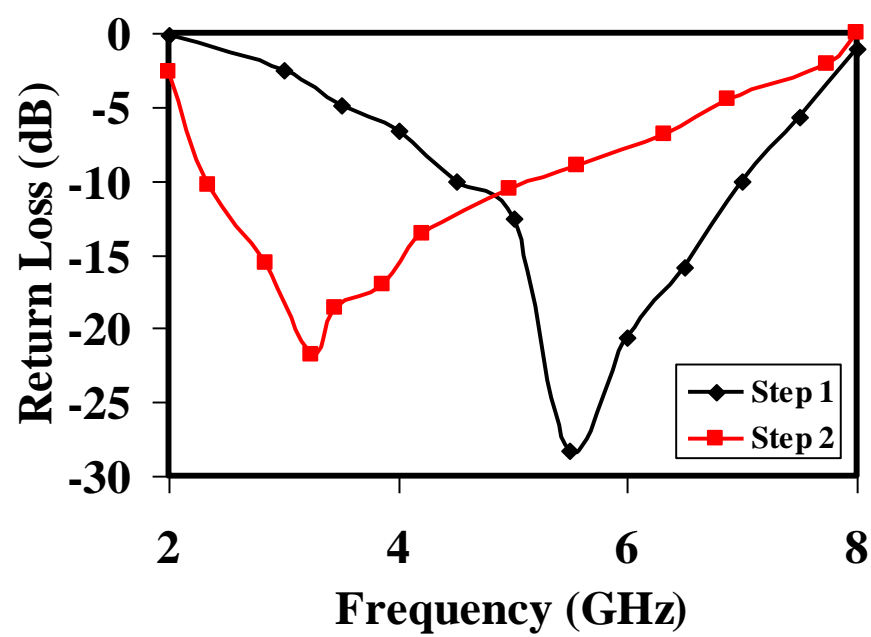

(c)

Fig.2. Configuration of Antenna (a) Antenna A (b) Antenna B (c) Antenna C.

Fig. 2 provides the study of single band antenna with antenna design shown by Fig. 2(a)-(b) and respective return loss of $-10 \mathrm{~dB}$ bandwidth by Fig. 2(c). For the initial design consisting of hexagon patch and rectangular ground plane provides resonance at $5.53 \mathrm{GHz}(\mathrm{RL}=-28.32)$ and covers bandwidth of $4.52 \mathrm{GHz}-7.11 \mathrm{GHz}$. To further decrease the resonant frequency, Step 1 is modified by embedding ellipse on hexagon patch leading to completion of Step 2 which gives new resonance frequency at $3.31 \mathrm{GHz}(\mathrm{RL}=-21.85)$ and bandwidth of $2.35 \mathrm{GHz}-4.98 \mathrm{GHz}$. At this stage of design, it is possible to convert proposed single band antenna to multiband antenna.

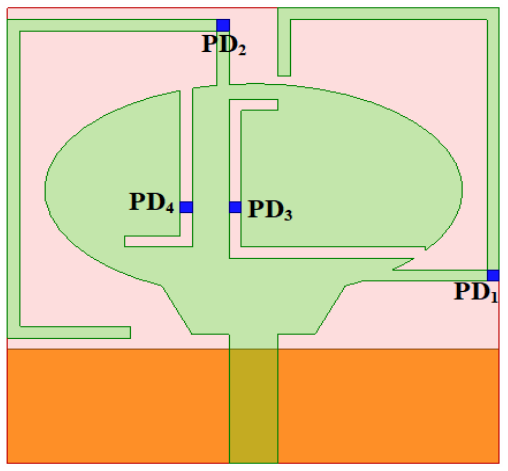

(a)

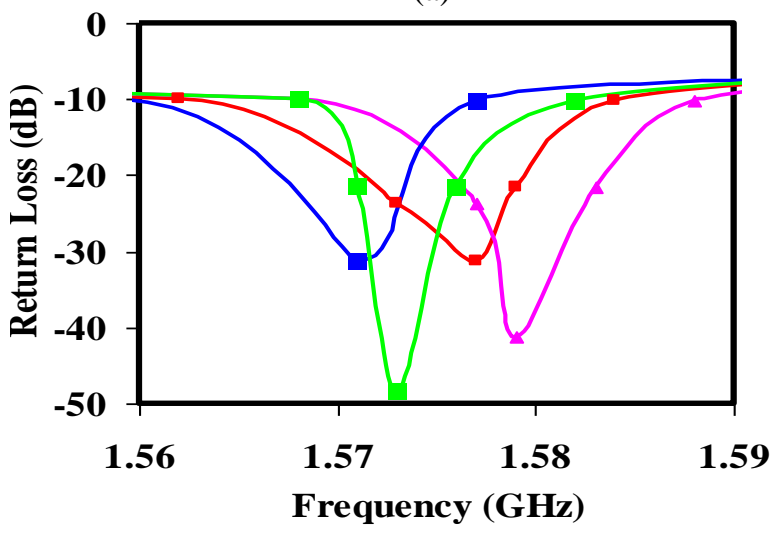

Subfigure of (b) 


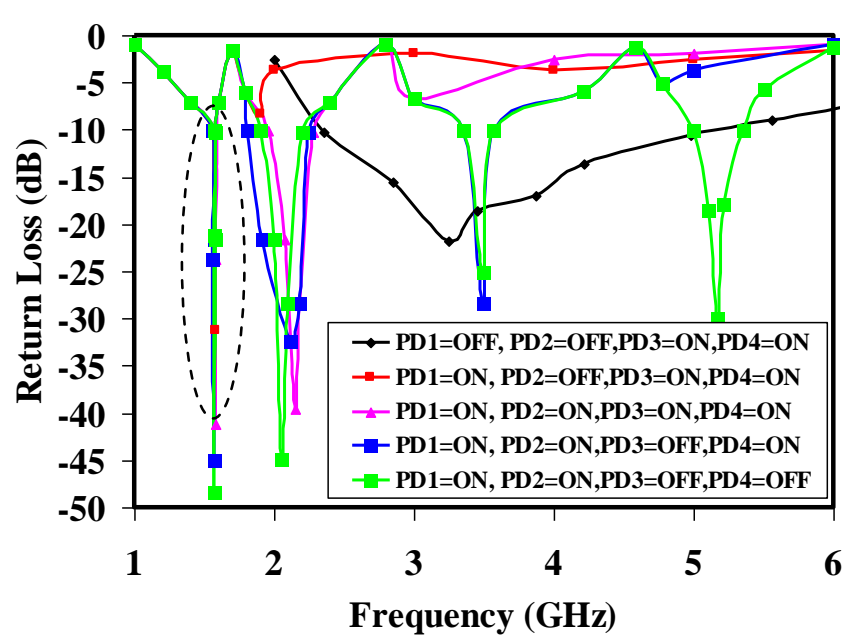

Fig.3. (a) Multiband Antenna (b) Return loss curve for various condition of PIN Diodes.

Fig. 3(a) illustrates front view of proposed antenna with multiband characteristics. Fig. 3(b) represents Return Loss curve for various ON/OFF conditions of PIN diodes and respective results are tabulated in Table II.

Table II: Analysis of proposed antenna

\begin{tabular}{|c|c|c|c|}
\hline Diode Condition & $\begin{array}{l}\text { Wireless } \\
\text { Applications }\end{array}$ & $\begin{array}{l}\text { Bandwidth } \\
\text { (GHz) }\end{array}$ & $\begin{array}{l}\text { Return Loss }(\mathrm{dB}) \\
\text { with Resonating } \\
\text { Frequency }(\mathrm{GHz})\end{array}$ \\
\hline $\begin{array}{l}\mathrm{PD}_{1}=\mathrm{OFF}, \mathrm{PD}_{2} \\
=\mathrm{OFF}, \mathrm{PD}_{3}=\mathrm{ON}, \\
\mathrm{PD}_{4}=\mathrm{ON}\end{array}$ & Single Band & $2.35-4.98$ & -21.85 at $3.25 \mathrm{GHz}$ \\
\hline $\begin{array}{l}\mathrm{PD}_{1}=\mathrm{ON}, \mathrm{PD}_{2} \\
=\mathrm{OFF}, \mathrm{PD}_{3}=\mathrm{ON}, \\
\mathrm{PD}_{4}=\mathrm{ON}\end{array}$ & GPS & $1.562-1.591$ & -31.33 at $1.577 \mathrm{GHz}$ \\
\hline $\begin{array}{l}\mathrm{PD}_{1}=\mathrm{ON}, \mathrm{PD}_{2} \\
=\mathrm{ON}, \mathrm{PD}_{3}=\mathrm{ON}, \\
\mathrm{PD}_{4}=\mathrm{ON}\end{array}$ & $\begin{array}{l}\text { GPS } \\
\text { UMTS }\end{array}$ & $\begin{array}{l}1.568-1.588 \\
1.96-2.28\end{array}$ & $\begin{array}{l}-41.22 \text { at } 1.579 \mathrm{GHz} \\
-39.65 \text { at } 2.15 \mathrm{GHz}\end{array}$ \\
\hline $\begin{array}{l}\mathrm{PD}_{1}=\mathrm{ON}, \mathrm{PD}_{2} \\
=\mathrm{ON}_{1} \mathrm{PD}_{3}=\mathrm{OFF}, \\
\mathrm{PD}_{4}=\mathrm{ON}\end{array}$ & $\begin{array}{l}\text { GPS } \\
\text { UMTS } \\
\text { WiMAX } \\
\end{array}$ & $\begin{array}{l}1.559-1.577 \\
1.81-2.25 \\
3.36-3.57 \\
\end{array}$ & $\begin{array}{l}-44.98 \text { at } 1.573 \mathrm{GHz} \\
-32.33 \text { at } 2.12 \mathrm{GHz} \\
-28.39 \text { at } 3.49 \mathrm{GHz}\end{array}$ \\
\hline $\begin{array}{l}\mathrm{PD}_{1}=\mathrm{ON}, \mathrm{PD}_{2} \\
=\mathrm{ON}, \mathrm{PD}_{3}=\mathrm{OFF} \\
\mathrm{PD}_{4}=\mathrm{OFF}\end{array}$ & $\begin{array}{l}\text { GPS } \\
\text { UMTS } \\
\text { WiMAX } \\
\text { WLAN } \\
\end{array}$ & $\begin{array}{l}1.568-1.582 \\
1.90-2.20 \\
3.36-3.57 \\
5.03-5.38 \\
\end{array}$ & $\begin{array}{l}-48.33 \text { at } 1.573 \mathrm{GHz} \\
-44.81 \text { at } 2.05 \mathrm{GHz} \\
-25.22 \text { at } 3.49 \mathrm{GHz} \\
-29.93 \text { at } 5.17 \mathrm{GHz}\end{array}$ \\
\hline
\end{tabular}

With condition $\mathrm{PD}_{1}=\mathrm{OFF}, \mathrm{PD}_{2}=\mathrm{OFF}, \mathrm{PD}_{3}=\mathrm{ON}$ and $\mathrm{PD}_{4}=\mathrm{ON}$ antenna provides single band operation. GPS band $(1.562 \mathrm{GHz}-1.591 \mathrm{GHz})$ is achieved when $\mathrm{PD}_{1}=\mathrm{ON}$, $\mathrm{PD}_{2}=\mathrm{OFF}, \mathrm{PD}_{3}=\mathrm{ON}$ and $\mathrm{PD}_{4}=\mathrm{ON}$ state. Under the condition $\mathrm{PD}_{1}=\mathrm{ON}, \quad \mathrm{PD}_{2}=\mathrm{ON}, \quad \mathrm{PD}_{3}=\mathrm{ON}$ and $\mathrm{PD}_{4}=\mathrm{ON}$ state, GPS wireless system including UMTS bands are achieved. Tri band applications are achieved $\mathrm{PD}_{1}=\mathrm{ON}, \mathrm{PD}_{2}=\mathrm{ON}$, $\mathrm{PD}_{3}=\mathrm{OFF}$ and $\mathrm{PD}_{4}=\mathrm{ON}$ state. Multiband antenna is achieved with resonating at four different frequencies covering GPS $(1.568 \mathrm{GHz}-1.582 \mathrm{GHz}, \quad-48.33$ at $1.573 \mathrm{GHz})$, UMTS $(1.90 \mathrm{GHz}-2.20 \mathrm{GHz}, \quad-44.81$ at $2.05 \mathrm{GHz})$, WiMAX (3.36GHz-3.57GHz, -25.22 at $3.49 \mathrm{GHz})$ and WLAN $(5.03 \mathrm{GHz}-5.38 \mathrm{GHz},-29.93$ at $5.17 \mathrm{GHz})$ wireless systems. To obtain this, $\mathrm{PD}_{1}=\mathrm{ON}, \mathrm{PD}_{2}=\mathrm{ON}, \mathrm{PD}_{3}=\mathrm{OFF}$ and $\mathrm{PD}_{4}=\mathrm{OFF}$ states are set.

\section{ANALYSIS OF SURFACE CURRENT DENSITY DISTRIBUTION, RESULTS AND DISCUSSION}

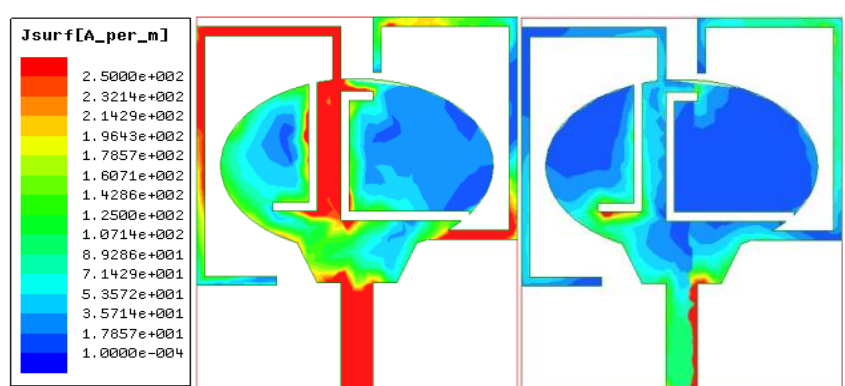

(a)

(b)

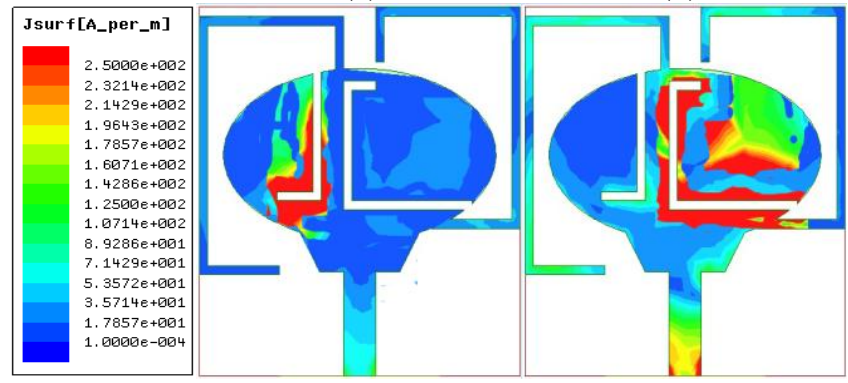

(c)

(d)

Fig.4. Surface current denity distribution at (a) $2.447 \mathrm{GHz}$ (b) $3.60 \mathrm{GHz}$ (c) $5.56 \mathrm{GHz}$ (d) $10.58 \mathrm{GHz}$.

Antenna behavior is also analyzed by studying surface current density distribution at resonating frequencies which are centered at $1.575 \mathrm{GHz}, 2.00 \mathrm{GHz}, 3.50 \mathrm{GHz}$ and $5.25 \mathrm{GHz}$ which are shown in Fig. 4(a)-(d). It I evident from Fig. 4(a)-(b) that the current density distribution is different for different resonant frequencies. For first and second resonant frequency centered at $1.575 \mathrm{GHz}$ and $2.00 \mathrm{GHz}$, large surface current density distribution is seen at corresponding stubs. Whereas, as observed from Fig. 4(c)-(d), large current density is observed around slots for resonating frequencies centered at $3.50 \mathrm{GHz}$ and $5.25 \mathrm{GHz}$ respectively with common feature that large current is also concentrated along CPW feed line.

To confirm the results obtained, simulated results are compared by using two simulators, EM Simulator Ansys HFSS and CST Microwave studio. Fig. 5 shows return loss curve obtained by both simulators and Table III tabulated values. From table, conclusion can be drawn that almost there is good agreement between both the simulated results confirming the design characteristics for multiband applications.

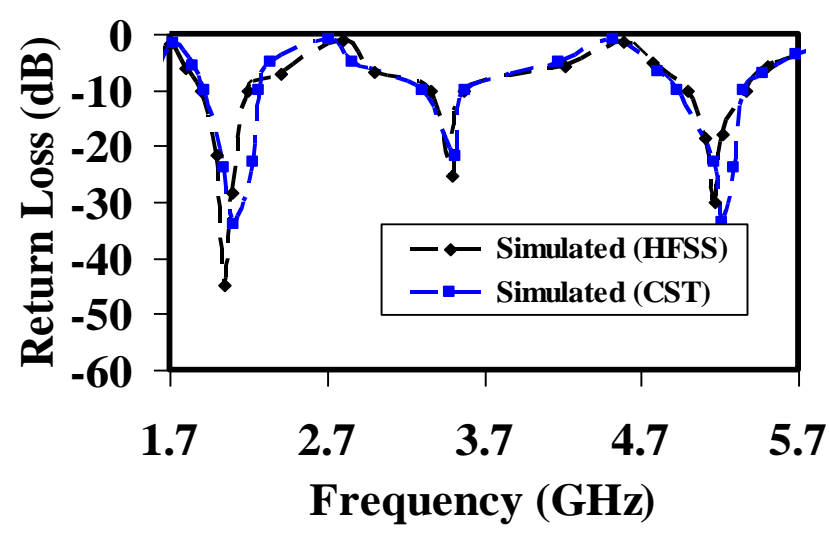

(a) 

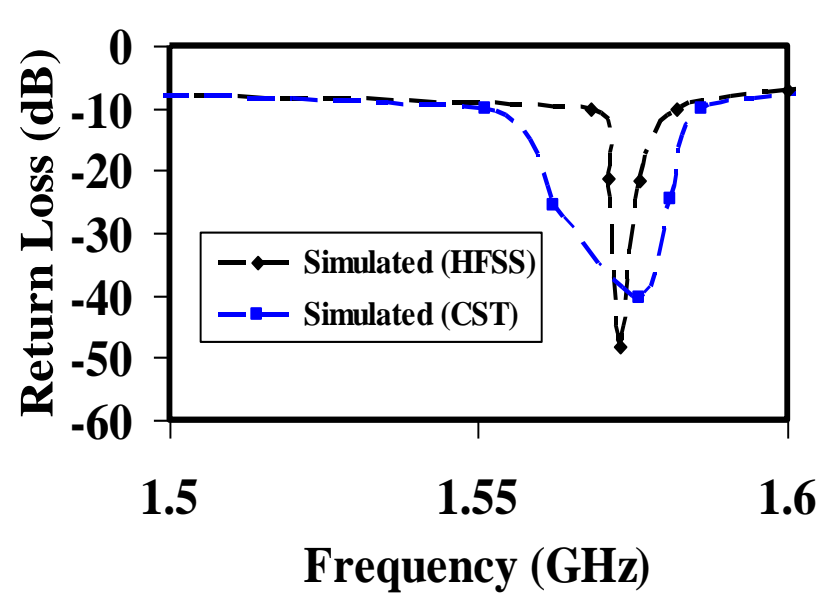

(b)

Fig. 5. Return Loss comparison (HFSS \& CST Microwave studio) (a) UMTS, WiMAX and WLAN bands (b) GPS application.

Table III: Return Loss Comparison

\begin{tabular}{|l|l|l|}
\hline Simulator & Bandwidth $(\mathbf{G H z})$ & $\begin{array}{l}\text { Return Loss (dB) with } \\
\text { Resonating Frequency } \\
\text { (GHz) }\end{array}$ \\
\hline & $1.568-1.582$ & -48.33 at $1.573 \mathrm{GHz}$ \\
HFSS & $1.90-2.20$ & -44.81 at $2.05 \mathrm{GHz}$ \\
& $3.36-3.57$ & -25.22 at $3.49 \mathrm{GHz}$ \\
& $5.02-5.36$ & -29.93 at $5.17 \mathrm{GHz}$ \\
\hline & $1.551-1.586$ & -40.289 at $1.576 \mathrm{GHz}$ \\
CST Microwave & $1.92-2.27$ & -33.987 at $2.11 \mathrm{GHz}$ \\
Studio & $3.31-3.58$ & -21.895 at $3.52 \mathrm{GHz}$ \\
& $4.93-5.35$ & -33.698 at $5.22 \mathrm{GHz}$ \\
\hline
\end{tabular}
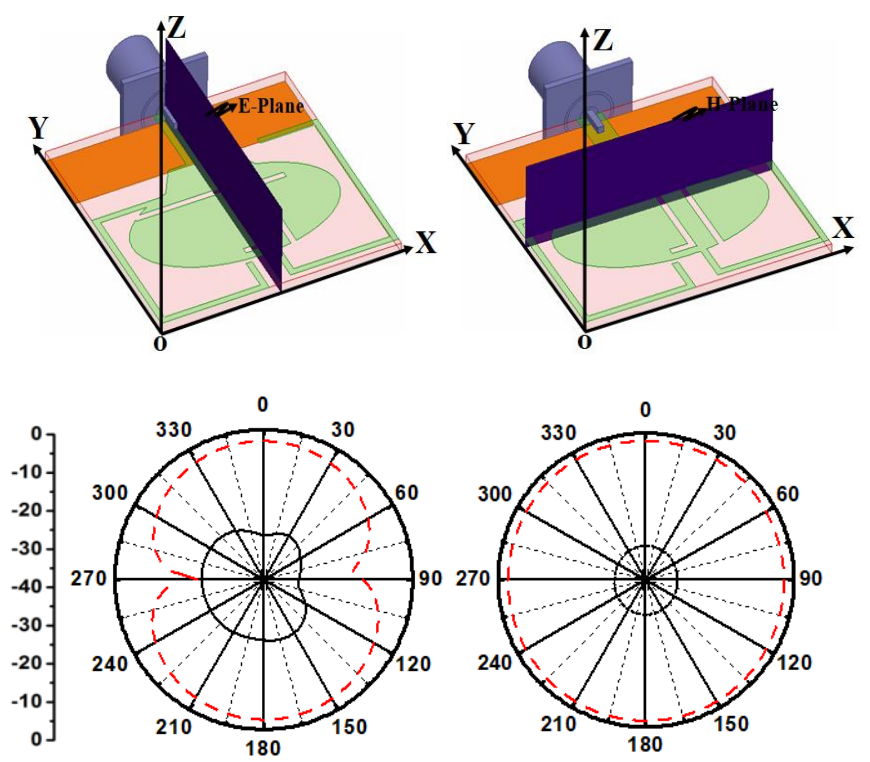

(a)
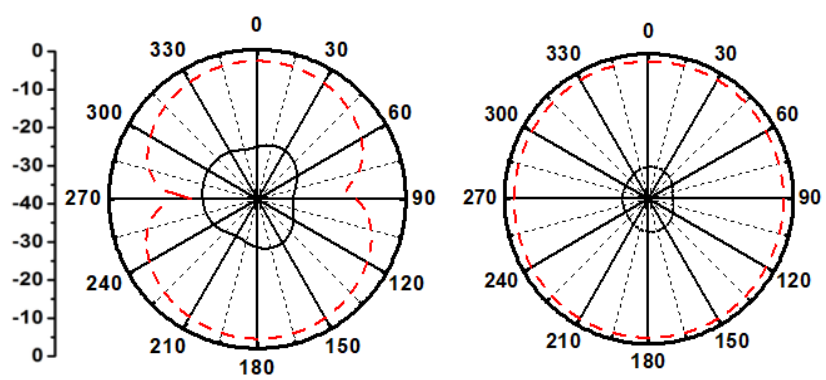

(b)
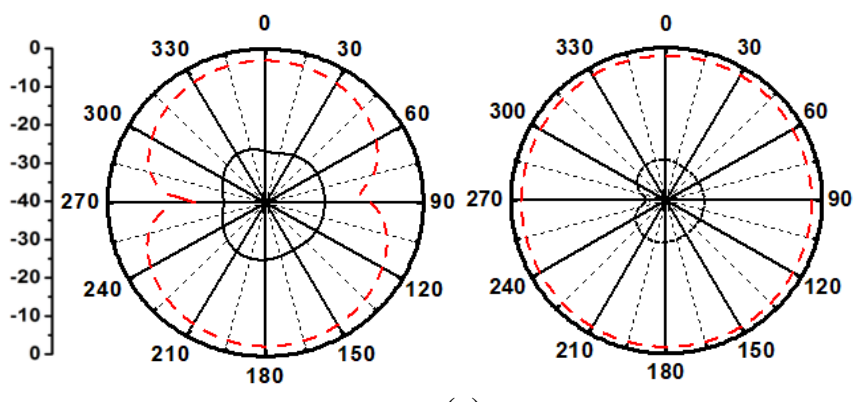

(c)
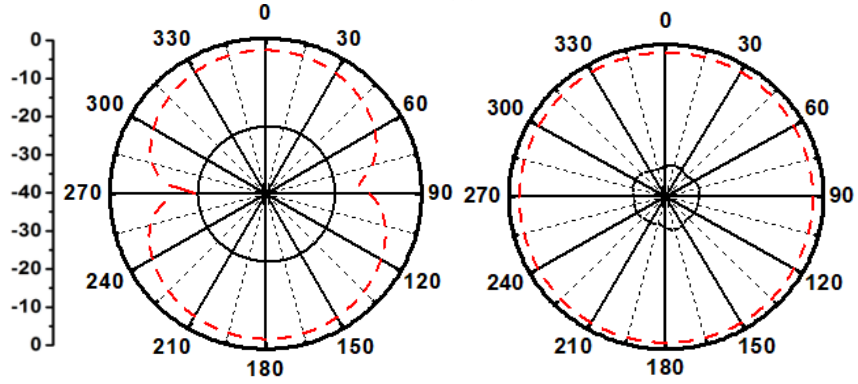

(d)

Co-polarization - - HFSS Cross-polarization

HFSS

Fig.6. Simulated normalized radiation patterns in E and H-plane (dB) at (a) $1.576 \mathrm{GHz}$ (b) $1.97 \mathrm{GHz}$ (b) $3.44 \mathrm{GHz}$ (b) $5.26 \mathrm{GHz}$.

Table III shows return loss comparison of two EM simulators HFSS and CST microwave studio obtained from Fig. 5. It can be concluded that there is very little variation with respective to operating bands for GPS, UMTS, WiMAX and WLAN bands due to working of simulators on different analytical platform.

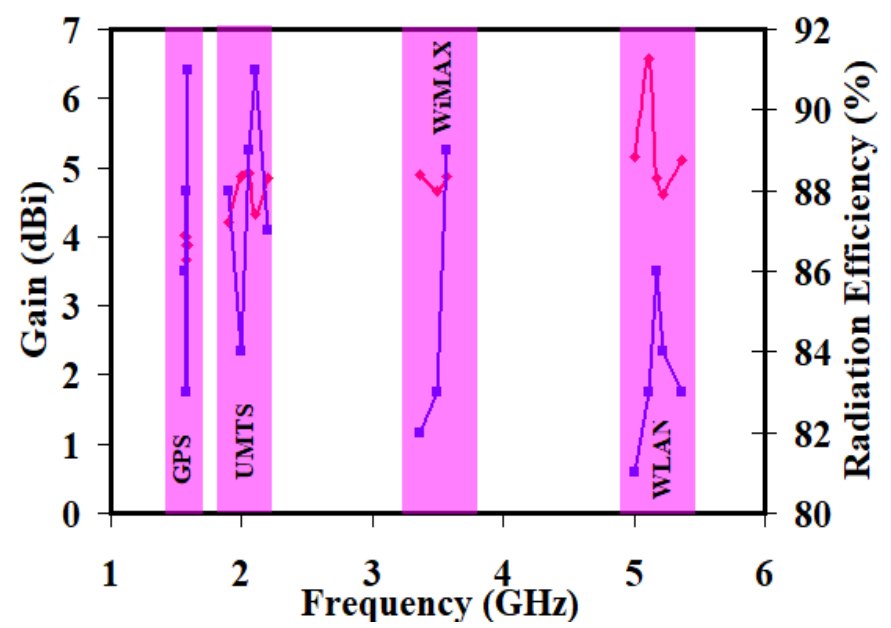

Fig.7. Gain of Antenna and Radiation Efficiency.

Normalized radiation pattern for frequencies $1.576 \mathrm{GHz}$. $3.58 \mathrm{GHz}, 3.44 \mathrm{GHz}$ and $5.26 \mathrm{GHz}$ are shown in Fig. 6 for E-plane and H-plane. It can be observed that there is good agreement between two simulators which shows omnidirectional pattern in H-plane and dipole like pattern in E-plane. 
Fig.7 represents gain of simulated antenna. For GPS wireless application, gain varies from $3.66 \mathrm{dBi}$ to $4.02 \mathrm{dBi}$. Similarly for UMTS, WiMAX and WLAN application, gain ranges between $4.22 \mathrm{dbi}-4.91 \mathrm{dBi}, 4.66 \mathrm{dBi}-4.89 \mathrm{dBi}$ and 4.62dbi-6.574dBi. Fig. 7 also represents radiation efficiency of antenna with maximum radiation of $91 \%$.

\section{CONCLUSIONS}

Miniaturized compact multiband antenna designed for Microwave substrate Rogers RTDuroid5870 is presented (Dimension: $20 \times 20 \times 0.787 \mathrm{~mm}^{3}$ ) for multiple wireless applications including GPS/UMTS/WiMAX/WLAN systems. Results are compared by using two simulators (HFSS and CST Microwave Studio) which are in good agreement with each other. Antenna has also good far field characteristics including maximum gain of $6.574 \mathrm{dBi}$, radiation efficiency of $89.63 \%$ and desirable radiation patterns.

\section{REFERENCES}

1. Y.I. Abdulraheem, G.A. Oguntala, A.S. Abdullah, H.J. Mohammed, R.A. Ali, R.A. Abd-Alhameed, and J.M. Noras, "Design of frequency reconfigurable multiband compact antenna using Two PIN diodes for WLAN/WiMAX applications," IET Microwaves, Antennas \& Propagation, vol. 11, no. 8, pp. 1098-1105, 2017.

2. T. Ali, M.M. Khaleeq, S. Pathan, and R.C. Biradar, "A multiband antenna loaded with metamaterial and slots for GPS/WLAN/WiMAX applications," Microwave Optical Technology Letters, vol. 60, pp. 79-85, 2017.

3. M.A. Kenari, M.N. Moghadasi, R.A. Sadeghzadeh, and B.S. Virdee, "Hexa-Band planar antenna with assymetric fork-shaped radiators for multiband and broadband communication applications," IET Microwaves, Antennas \& Propagation, vol. 10, no. 5, pp. 471-478, 2016.

4. P.S. Bakariya, S. Dwari, M. Sarkar, and M.K. Mandal, "Proximity coupled multiband microstrip antenna for wireless applications," IEEE Antennas and Wireless Propagation Letters, vol. 14, pp. 646-649, 2015.

5. Boukarkar, X.Q. Lin, J.W. Yu, P. Mei, Y. Jiang, and Y.Q. Yu, "A highly integrated independently Tunable Triple-Band notch antenna," IEEE Antennas and Wireless Propagation Letters, vol. 16, pp. 2216-2219, 2017.

6. R.S. Brar, K. Saurav, D. Sarkar, and K.V. Srivastava, "A quad-band dual-polarized monopole antenna for GNSS/UMTS/WLAN/WiMAX applications," Microwave Optical Technology Letters, vol. 60, pp. 538-545, 2018

7. S. Chen, M. Fang, D. Dong, M. Han, and G. Liu, "Compact multiband antenna for GPS/WiMAX/WLAN applications," Microwave Optical Technology Letters, vol. 57, pp. 1769-1773, 2015.

8. H.R. Cheong, K.H. Yeap, K.C. Lai, P.C. Teh, and H. Nisar, "A compact CPW-fed antenna with fractal S-shaped patches for multiband applications," Microwave Optical Technology Letters, vol. 59, pp. 541-546, 2017

9. L. Kumar, A. K. Gautam, B. K. Kanaujia, and K. Rambabu, "Design of Compact F-shaped slot triple band antenna for WLAN/WiMAX applications," IEEE Transactions on Antennas and Propagation, pp. $1-6,2015$.

10. A.R. Jalali, J.A. Shokouh, and S.R. Emadian, "Compact multiband monopole antenna for UMTS, WiMAX and WLAN applications," Microwave Optical Technology Letters, vol. 58, pp. 844-847, 2016.

11. M. Moosazadeh, and S. Kharkovsky, "Compact and small planar monopole antenna with symmetrial L- and U-shaped slots for WLAN/WiMAX applications," Microwave Optical Technology Letters, vol. 13, pp. 388-391, 2014.

12. Z. Yu, J. Yu, X. Ran, and C. Zhu, "A novel Koch and Sierpinski combined fractal antenna for $2 \mathrm{G} / 3 \mathrm{G} / 4 \mathrm{G} / 5 \mathrm{G} /$ WLAN/Navigation applications," Microwave Optical Technology Letters, vol. 59, pp. 2147-2155, 2017.

\section{AUTHORS PROFILE}

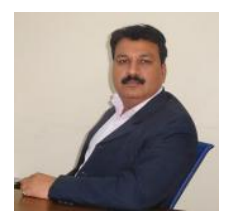

Prof.(Dr.) Manoj Kapil is currently working as Principal, Subharti Institute of Technology \& Engineering, Subharti University Meerut, Uttar Pradesh, India. He is a distinguished academician with over 16 years of experience in Computer Science and Engineering. $\mathrm{He}$ is M.Tech(CSE), M.Phil.(CS), Ph.D.(CS) and having several International publications in IEEE, Springer and other reputed journals; Published two books on web technology and guided several undergraduate, post-graduate and $\mathrm{PhD}$ research works. $\mathrm{He}$ has developed more than 80 websites and web-based ERP systems. He has delivered various lectures on cybersecurity \& ethical hacking and has given consultations on several criminal cases to SOG, Dehradun. He started his career as a Software Engineer in 4CPlus Ltd. and was associated with DRDO for developing expert systems.

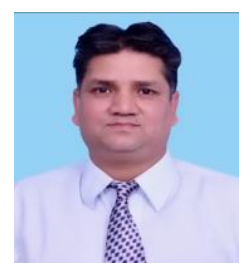

Dr. Manish Sharma Completed Ph.D in RF and Microwave from Banasthali Vidyapith in 2017. He completed M.Tech from VTU Belgaum in 2007 and B.E from Mangalore University in 2000. He has published research articles in peer review journals with high impact factor such as IEEE, Taylor \& Francis, Elsevier, Frequenz, Cambridge Press, Springer, Inderscience etc. He has also published more than 30 research articles in IEEE conferences. He has received best presentation award at 6th Edition of International Conference on Wireless Networks and Embedded Systems, Chitkara University, 16-17th November, 2018.

$\mathrm{He}$ is currently working as Associate Professor in Electronics and Communication Engineering, SGT University, Gurugram, India. His research interest includes UWB antennas, RFID antennas, planar Microwave filters, Phase Shifter MIMO antennas and Planar antenna on Si Substrate. 